\title{
FUNCTIONAL AND COMPARATIVE STUDY OF THE CIRCUMVALLATE PAPILLAE IN FOUR SPECIES OF MAMMALS
}

\author{
Gihan S. Hassan*, Reda G. Saleh* and Amel M. Ezzat Abdelhamied**
}

\begin{abstract}
Introduction: The mammalian tongue displays significant morphological differences. These differences seemed to be related to the nature of food. Also, the surrounding environmental conditions play an important role in these differences. The dorsal mucosa of the tongue is covered by numerous papillae. In many mammals, tongue papillae play a vital role in food intake and digestion.
\end{abstract}

The aim study: This study was to investigate the morphological characteristics of the circumvallate papillae (CVPs) of rat, dog, rabbit and goat.

Materials and Methods: For this purpose, tongues of these animals were examined macroscopically as well as with light and scanning electron microscope (SEM).

Results: Grossly observations reveled, in ratsa single large CVP surrounded by a semicircular moat and an indistinct annular pad. In dogs, five CVPs were arranged in two lines. The large papillae were surrounded by a wide moat and a prominent annular pad. Whereas, the small papilla lacked the annular pad and had irregular ridges.In rabbits, two CVPs enclosed by a deep moat lacking the annular pad. Whereas, goats had eight pairs of CVPs on both rims of the torus linguae and were encircled by a prominent gustatory moat and a thick annular pad. Histological examination of the four species revealed taste buds were located in the medial and lateral walls of the moat except for goats that had taste buds only in the medial wall of the moat. SEM examinationof the papillary surface exposedtransverse grooves in rats, irregular microridges and grooves in dogs and rabbits whereas the goats showed very little and small grooves.

Conclusion: Hence, this study highlighted a variation in the morphology and microscopic anatomy of CVPsas an adaptation to their different feeding behaviours.

KEYWORDS: Circumvallate, tongue, rat, dog, rabbit, goat, scanning electron microscope.

* Lecturer of Oral Biology, Faculty of Dentistry, Tanta University, Egypt.

** Ass. Professor of Oral Biology, Faculty of Dentistry, Tanta University 


\section{INTRODUCTION}

The mammalian tongue displays significant morphological differences which seem to be related to the nature of food and the surrounding environmental conditions. ${ }^{1}$ Tongue accomplishes the required functions, such as swallowing, water uptake, manipulating the food, grooming, vocal modulation and suckling. ${ }^{2,3,4}$ In addition, it participates in the secretion of saliva and tasting food. ${ }^{5}$

The dorsal mucosa of the tongue is covered by numerous papillae which play a vital role in food intake and digestion in many mammals. ${ }^{6,1,7}$ Moreover, studies reveal variations in the morphology and the distribution of papillae on the dorsal lingual surface among animal species, ${ }^{8} \mathrm{dog},{ }^{9}$ mongoose,${ }^{10}$ Japanese weasel, ${ }^{11}$ sea otter, ${ }^{12}$ bush $\operatorname{dog},{ }^{13}$ panther and Asian black bear ${ }^{14}$ and silver fox. ${ }^{15}$

The lingual papillae are divided into mechanical and gustatory papillae in relation to their functions. Mechanical papillae may be involved in the friction between the tongue and food substances and they include three types; filiform, fungiform and conical papillae.Whereas, gustatory papillae contain taste buds that serve in taste reception and they comprise fungiform, circumvallate and foliate papillae. ${ }^{16}$

The CVPs are generally situated on the posterior third of the tongue in all animals and are usually surrounded by acircular groove. Kubota $1988^{17}$ reported a relation between the development of CVPs with their feeding habits and the environment. In addition, several studies found variation in the number as well as the distribution of these papillae and their taste buds among species. ${ }^{13,18-24}$ The epithelium of the CVPs contains many taste buds that may be considered as sensory organs which respond to numerous taste stimuli. ${ }^{25}$ They are onionshaped structures specialized for the detection of aqueous stimuli. ${ }^{26}$

Remarkably, Iwasaki $2002^{1}$ pointed out that studying the tongue, in conjunction with other anatomical characters, serves as a useful indicator of habits and diet of animals, and may also provide important information for taxonomic purposes.

In this study, CVPs will be investigated in four animals from different orders of animals; rodents (rats), carnivores (dogs); lagomorphs (rabbits) and ruminants (goats) as they represent the species of choice for experimental studies used for medical, economical and teaching purposes.

\section{MATERIALS AND METHODS}

\section{Sample collection and tissue preparation}

In this study, five tongues of mature male rats (Albino rat), dogs (Canisfamiliaris), rabbits (Oryctolagus cuniculus f. domestica) and goats (Baladi goats) were used in this study. All animals were healthy and clinically normal. The tongues of rats and dogs were collected after killing the animals with the appropriate anesthetics (i.e. chloral hydrate in rats, xylazine-ketamine in dogs). On the other hand, the tongues of rabbit and goat were collected directly after slaughtering the animals at kafrEl Sheikh slaughter houses. All animal experiments were reviewed and approved by the Research and Ethical Committee of the Faculty of dentistry, Tanta University. Tongue specimens were washed with the normal saline solution $(0.9 \%)$, and then three specimens of each animal were fixed in in $10 \%$ buffered formalin for light microscopic study and the others were fixed in 2-4\% phosphate buffered Glutaraldehyde and formaldehyde $\mathrm{pH} 7.3$ for scanning electron microscopic study.

\section{Macroscopic study}

The gross anatomy of all tongues wasexamined from both fixed and fresh specimens. The examination of the tongue included position, shape, number and surrounding structure of the CVP in each animal.

\section{Light microscopic study}

Specimens were fixed in $10 \%$ buffered formalin for $24 \mathrm{~h}$. Then, they were washed in tap water over night and then dehydrated in ascending grades of 
alcohol, cleared in xylene and then embedded in low melting point $\left(56^{\circ} \mathrm{C}\right)$ paraffin. Serial sections of 5 um thickness were processed for H\&E. ${ }^{27}$

\section{Scanning electron microscopic study}

The specimens were fixed in 2-4\% phosphate buffered Glutaraldehyde and formaldehyde $\mathrm{pH} 7.3$ for $24 \mathrm{~h}$. Then, they were washed twice in buffer to remove any unreacted aldehyde. Postfixation was performed with $0.2 \%$ osmium tetroxide followed by washing in PBS and dehydration in ascending grades of alcohol followed by two washes in acetone. After that the specimens were fixed on a stump and coated with gold by sputter coater (Denton Desk II, Denton Vacuum LLC, Moorestown, NJ, USA ${ }^{28}$ and examined with SEM (JSM 5600LV, Jeol, Tokyo, Japan) in EM Unit of Faculty of Medicine, Tanta University.

\section{RESULTS}

\section{Macroscopic observations}

\section{Rat}

The tongue of therat was elongated consisting of tip with a rounded apex, body and root. Single CVP, oval or rounded in shape, appeared in the middle of the posterior one-fourth of the tongue. It was prominent, measured $1-2 \mathrm{~mm}$ in diameter and was surrounded by a semicircular moat and an indistinct annular pad. The anterior end of the papilla was continuous with the adjacent tongue surface. Whereas, the posterior and lateral parts of the papilla were separated from the adjacent tongue surface by a narrow moat (Fig.1.A\&B).

\section{Dog}

The tongue of thedog was widely flattened. Two CVPs were arranged close to each other forming a line on either side of the midline of the tongue, and the two lines diverged anteriorly on the dorsal surface. On each side, two papillae measured 2-3 $\mathrm{mm}$ in diameter and were surrounded by a wide moat and a prominent annular pad in the majority of specimens. However, the third small papilla lacked the annular pad and had irregular ridges (Fig.1.C,D\&E).

\section{Rabbit}

The tongue of therabbit was characterized by an elongated corpus, which was relatively flat and ended with a rounded apex. Also, it had a prominent posterior lingual prominence (torus lingua). It was large for the size of the animal. There were two CVPs in the posterior part of the body of the tongue, just posterior to the lingual prominence. The CVP was rounded in shape, one in each side of the midline. They measured about $2 \mathrm{~mm}$ in diameter and were surrounded by a moat (Fig.2.A\&B).

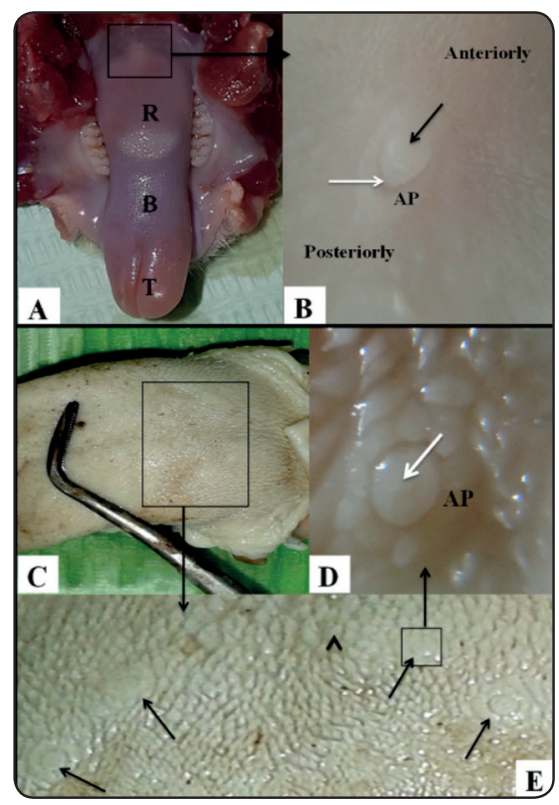

Fig. (1): A\&B Photographs of rat tongue showing:A. Elongated tongue tip with a rounded apex (T), body $(\mathrm{B})$ and root $(\mathrm{R})$. B. (Higher magnification of figure A) One oval CVP (black arrow) with a semicircular moat posteriorly(white arrow) and an indistinct annular pad (AP). C, D\&E Photographs of dog tongue showing:C. Widely flattened tongue. D. (Higher magnification of figure E) CVP surrounded by a wide moat (white arrow) and a prominent annular pad (AP). E. (Higher magnification of figure C) Two large CVPs arranged close to each on either side of the midline of the tongue (black arrows) and one small papilla which lack an annular pad (arrowhead). 


\section{Goat}

The tongue of thegoat appeared long with a sharp rounded anterior edge and a flattened apex like a spatula. Eight pairs of CVPs were noticed round to oval in shape and were present on both rims of the torus linguae in the posterior part of the tongue. Their measurements ranged from 1-3 $\mathrm{mm}$ in diameter. They were encircled by a prominent gustatory moat and a thick annular pad. Occasionally, two adjacent CVP were surrounded by a common annular pad being separated by a secondary moat (Fig.2. C\&D)

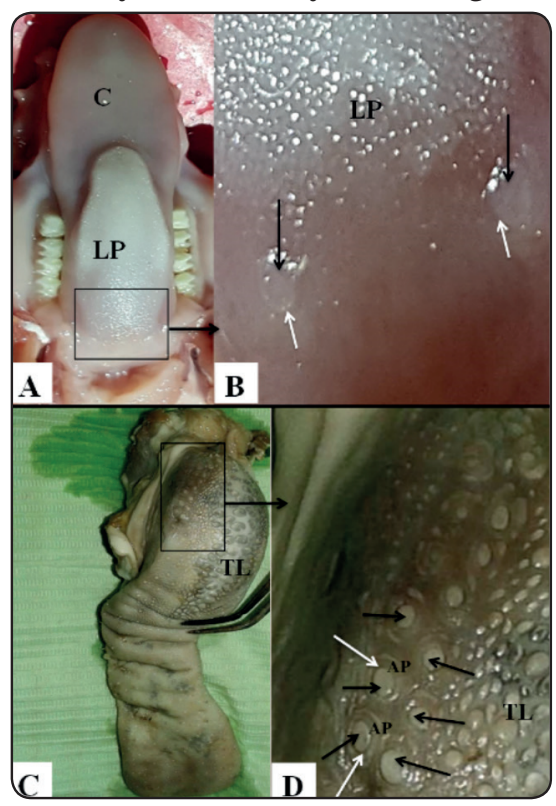

Fig. (2): A\&B Photographs of rabbit tongue showing: A. Elongated, flat corpus $(\mathrm{C})$, posterior lingual prominence (LP). B. (Higher magnification of figure A) Two CVPs (black arrows) posterior to lingual prominence (LP) surrounded by a moat (white arrows). C\&D Photographs of goat tongue showing:C. Long tongue with flattened apex and torus linguae (TL) posteriorly. D. (Higher magnification of figure C) Eight pairs of CVPs (black arrows), torus linguae (TL), a prominent gustatory moat (white arrow) and a thick annular pad (AP).

\section{Light microscopic observations}

\section{Rat}

CVP appeared surrounded by a narrow moat with variant depth. Large number of taste buds were found along the entire length of the lateral and medial walls of the moat. The taste buds extended along the entire thickness of the epithelial wall. Taste pores were clearly visible and opened into the moat. Lingual serous SG appeared mostly above the tongue muscles, they drained their secretion through the excretory ducts into the moat of the papilla (Fig.3.A, B,C\&D).

\section{Dog}

CVP had a deep moat, lined with keratinized stratified squamous epithelium. Surface epithelium appeared with indentations and multiple long papillae, while the sides were covered with thin nonkeratinized stratified squamous epithelium. In addition, some taste buds were also observed in the epithelium at the junction between the surface and the medial wall. The large CVP showed secondary papillae and grooves. Taste buds were frequent in both the medial and lateral walls of the moat. It had a core of connective tissue (CT) with bundles of collagen fiber and blood capillaries. However, numerous secondary connective tissue cores were revealed along the lateral sides of the papillae specially the small one. Few lingual serous salivary glands (SG) were located in the lamina propria and submucosa while most of the glands were located between the muscle bundles (Fig.3. E,F,G\&H).

\section{Rabbit}

CVP had a deep moat and thick irregular KEsurface with short papillae. It had a core of CT with collagen fibers and blood capillaries. Taste buds were continuously observed in the medial and lateral walls of the moat which was characterized by a very thin NKE. Taste buds were oval bodies that extended through the thickness of the epithelium. Numerous lingual serous salivary glands appeared mostly between the tongue muscles, they drained their secretion through the excretory ducts into the moat (Fig. 4. A,B,C\&D). 


\section{Goat}

CVP was large, flattened, well circumscribed papillae and was encircled by a prominent gustatory moat. The epithelium of the dorsal surface of the papilla appeared slightly KEbut thin NKEon the sides which bear many taste buds. Taste buds were continuously observed in the medial wall of the gustatory moat while they were absent from lateral walls. The lamina propria appeared as a dense network of CT, blood vessels, and tongue skeletal muscles bundles that run in transverse, longitudinal and oblique directions. Numerous small lobules of the serous secreting acini were stained darkly with $(\mathrm{H} \& \mathrm{E})$; they were located in the lamina propria, sub mucosa and between the muscle bundles. They drained their secretion through the excretory ducts into gustatory moat (Fig.4. E, F, G\&H).
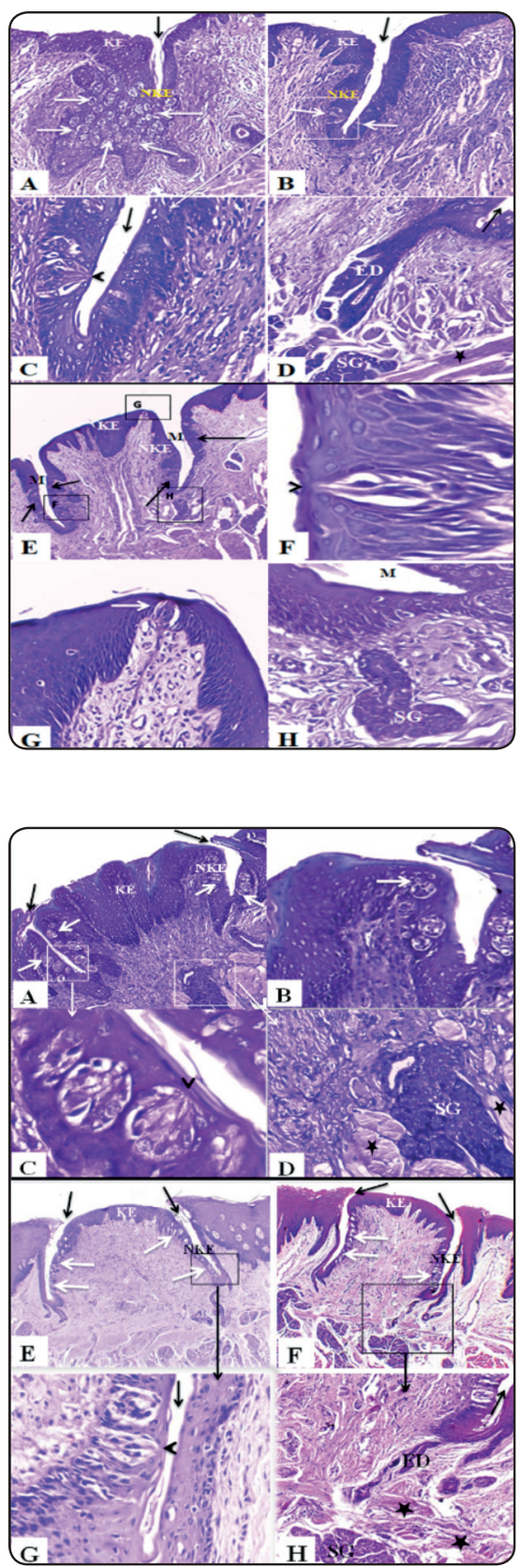

Fig. (3):A, B , C\&D Photographs of rat tongue showing: A\&B. CVP with a narrow moat (black arrow), irregular keratinized epithelial surface (KE), thin nonkeratinized epithelium (NKE). Large number of taste buds in both walls of the moat (white arrows). C. (Higher magnification of figure B) Taste buds with apical pore (black arrowhead) opens into the moat (black arrow). D. Serous salivary glands (SG) above tongue muscles (star). Excretory ducts (ED) CVP moat (black arrow). E, F, G\&H photographs of dog tongue showing. E. CVP with a deep moat (M), KE with multiple long papillae. NKE in lateral surface, taste buds in both walls of the moat (black arrows). F. (Higher magnification of figure E) Pore of a taste bud(black arrowhead). G. (Higher magnification of figure E) Taste bud at the junction between surface epithelium and lateral wall (white arrow). H. (Higher magnification of figure E) Serous salivary glands (SG) in the lamina propria below CVP moat (M). (H\&E orig. mag., A, B\&E ×10, C, D, F, G\&H×40).
Fig. (4): A, B , C\&D photographs of rabbit tongue showing: A. CVP with a deep moat (black arrows) and thick irregular KE with short papillae. Very thin NKE in the lateral surface, taste buds in both walls of the moat (white arrow). B. Taste buds at the junction between surface epithelium and lateral wall (white arrow). C. (Higher magnification of figure A) Taste buds with apical pore (black arrowhead). D. (Higher magnification of figure A) Serous salivary glands (SG) between tongue muscles (star). E, F, G \& H photographs of goat tongue showing: E\&F. CVP with a prominent moat (black arrows), slightly KE with short papillae. Thin NKE in the lateral surface with many taste buds in the lateral walls of the moat (white arrows). G. (Higher magnification of figure E) Taste buds with apical pore (black arrowhead). H. (Higher magnification of figure F) Serous salivary glands (SG) in the lamina propria, submucosa and between the muscle bundles (star). Excretory ducts (ED). (H\&E orig. mag., A, E\&F ×10, B, C, D , G\&H×40). 


\section{Scanning electron microscopic observations}

\section{Rat}

CVP of the rat appeared oval in shape surrounded by a semicircular relatively deep moat and an indistinct annular pad. The anterior end of the papilla appeared continuous with the adjacent lingual surface, and easily distinguished from the closely related conical papillae. However, the posterior and lateral parts of the papilla were separated from the conical papillae of the adjacent tongue surface by a narrow groove and an indistinct annular pad. The papillary surface presented transverse grooves and elevations runningmediolaterally along the posterior parts (Fig.5. A, B, C\&D).

\section{Dog}

CVP of the dog had a mushroom shape from the longitudinal cut section view. CVP was depressed under the tongue surface and was anchored at the bottom by a short stalk. It was surrounded by a deep wide moat and a prominent annular pad which was interrupted with irregular moats. The surface of the papilla had irregular microridges and grooves that mostly appeared numerous in the large papilla (Fig. 5. E,F,G\&H)

\section{Rabbit}

CVP of the rabbit had a mushroom shape from longitudinal cut section view and was depressed under the tongue surface. However, it was anchored at the bottom by a broad stalk. It was surrounded by a deep moat without an annular pad. The surface of the papilla had irregular and several microridges surface. Taste pore appeared on the lateral wall of the CVP (Fig. 6. A, B, C\&D).

\section{Goat}

CVP of goat tongue were noticed round to oval in shape from top view and were present encircled by a prominent deep gustatory moat and a thick annular pad. From longitudinal cut section view, they appeared as a mushroom shape and were depressed under the surface of the tongue. At higher magnification, stratified scales with very little and small grooves appeared on the dorsal surface of the papilla and the taste pores were positioned along the lateral surface of the papilla opening into the papillary moat (Fig.6. E, F, G\&H).

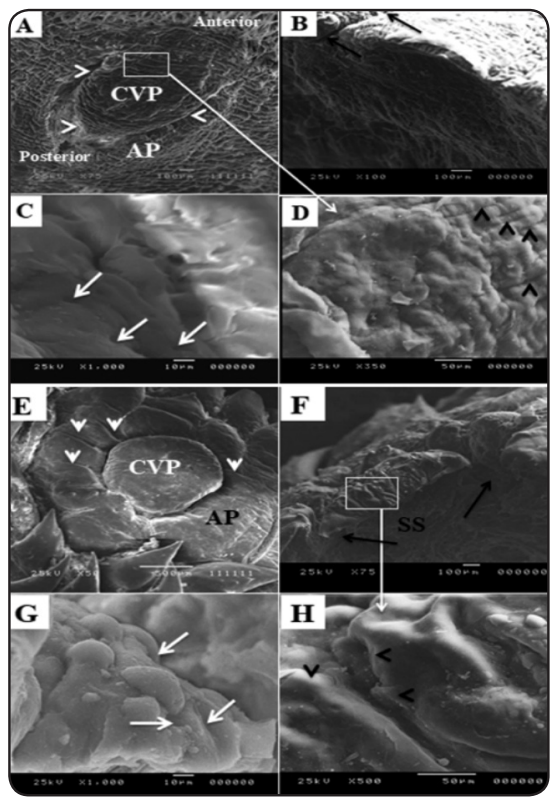

Fig. (5):A, B, C\&D SEM photographs of dog tongue showing:A. Top view of CVP surrounded by a semicircular moat (white arrowheads) and an indistinct annular pad (AP). B. The longitudinal anteroposterior cut section view of CVP with incomplete relatively deep moat (black arrow). C. Higher magnification of CVP lateral surface showing taste pores (white arrow). D. Higher magnification of CVP top surface showing transverse grooves and elevations that run mediolateral (black arrowheads). E, F, G\&H photographs SEM of dog tongue; E. Top view of CVP surrounded by a prominent annular pad (AP) interrupted with irregular moats (white arrowheads). F. The longitudinal cut section view of CVP that was depressed under the tongue surface, anchored at the bottom by a short stalk (SS), a deep wide moat (black arrow). G. Higher magnification of CVP lateral surface showing taste pores (white arrows). H. Higher magnification of CVP top surface showing irregular microridges (black arrowheads). (A x75, B x100, C\&G x1000 \& D x350. E x50, F x75, \& H x500). 


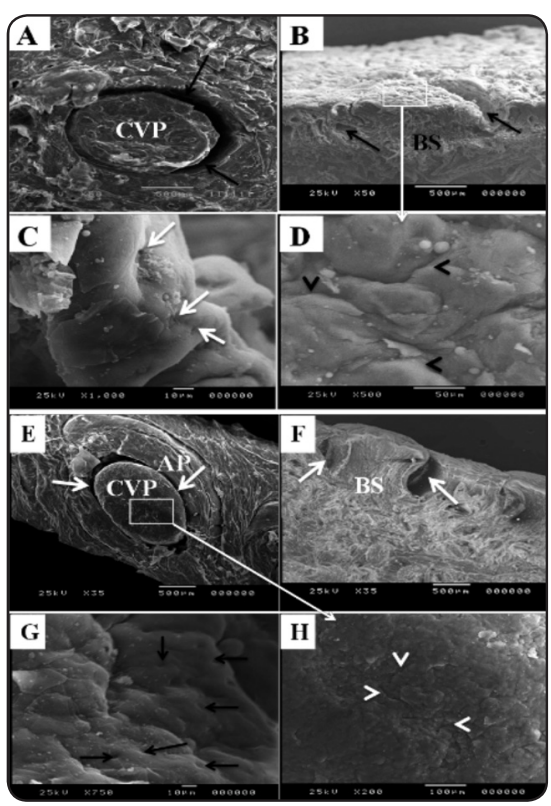

\section{DISCUSSION}

Most of the investigations designed to examine the influence of various factors on the human body are performed on animals. Thus, studying the normal structure of any organ is fundamental for the accomplishment of these investigations. ${ }^{29}$

Generally, the tongue has an importantrole in feeding with other organs of the body. ${ }^{1}$ This role is associated with the morphology, structure and distribution of the lingual papillae. ${ }^{30} \mathrm{CVPs}$ are the largest papillae that harbors a great number of taste buds. CVPs are important in perception ofbitter taste which participate in avoiding noxious or poisonous substances. ${ }^{31}$

The available literature reveals that CVPs particularly of these four animals have not been comprehensively investigated thus this study provided a detailed macroscopic, light and scanning electron microscopic description.

In light of the present findings, the tongue revealed disparity in the four species. In rat, a large CVP was observed in the middle of the posterior fourth of the tongue. This is contradictory to Abayomi et al. 200932 who reported very few CVPs in the posterior of the tongue of Rat (Rattus
Norvegicus) as well as Davydova et al.2017 29 who described one large CVP and similar smaller CVP in Albino rats. However, this corresponded to Iwasaki et al. $1988^{33}$ who reported one CVP in squirrel monkey.

Moreover, among the rodents the CVPs number were diverse..$^{29}$ The one large CVP on the posterior part on the medial line of tongue was described not only in Albino rat but also in mice,,$^{31,34}$ hamsters $^{35}$ and bank vole. ${ }^{36}$ Whereas, two CVP on both sides of posterior part of tongue were traced in blind mole rat $^{37}$ and guinea pig $^{38}$ and three CVP were demonstrated in Flying squirrel,,$^{39}$ shrew $^{40}$ and American beavers ${ }^{41}$ The tongues of Albino rats had a macroscopic structure comparable to the tongues of other rat species ${ }^{42}$ like wild rat, ${ }^{43}$ Sprague-Dawley rat $^{44.45}$ and Wistar rat. ${ }^{44,46}$

Under light microscope, it was surrounded by a narrow moat with a large number of taste buds along the lateral and medial walls of the moat. This agreed with the structure of the rat tongue described by Hosley and Oakley 198747; Wakisaka et al., 199848; Triantafyllou et al. 2002 $2^{49}$; Picoli et al. 2006 ${ }^{50}$; Costa et al. 201344; Al-Refai et al. 2014 ${ }^{42}$; El Sharaby et al. $2014^{51}$ and Reginato et al. 2014. ${ }^{45}$ SEM 
examination of rat CVP disclosed a large papilla surrounded by a semicircular moat and an indistinct annular pad which is continuous with the adjacent lingual epithelium anteriorly. Also, transverse grooves and elevations were observed on the surface. These observations were in accordance with Iwasakiet al. 1997 ${ }^{19}$,Yücel et al. 2002 ${ }^{52}$, Ghazale and Frangis $2013^{53}$, El Sharaby et al. 2014,,$^{54}$ Davydova $2017^{29}$ and Goździewska-Harłajczuk 2018. ${ }^{55}$

In dog, two types of papillae four large and one small CVP were observed arranged in two lines that diverged anteriorly on the dorsal surface.Previously, it was thought to have a pair of CVP on each side of the midline. These findings confirmed preceding observations in $\operatorname{dogs}^{13,56}$ and othercarnivores like cats $^{57}$ and raccoon dogs. ${ }^{58}$ Light microscopic examination showed CVP had a deep moat. Taste buds were observed in the medial wall and lateral walls of the moat as reported by El Sharaby et al. $2014{ }^{51}$ and Kobayashi etal. $1988 .{ }^{56}$ SEM examination showed large CVP surrounded by a prominent annular pad and interrupted with secondary grooves and irregular moats. The surface of the papilla had irregular grooves mostly in the large papilla. This agreed with preceding observations in $\operatorname{dogs},{ }^{54}$ the bush $\operatorname{dog}^{13}$ and the Raccoon Dog. ${ }^{58}$

Whereas, Rabbits showed two CVP in the posterior part of the body of the tongue, just posterior to the lingual prominence. Thus CVPs were comparable in shape to cows,${ }^{59}$ horses,${ }^{60}$ squirrel monkey ${ }^{33}$ and guinea pigs. ${ }^{57}$ Light microscopic examination showed CVP were lined by thick irregular keratinized epithelium. Taste buds were detected in the medial and lateral walls of the moat. These coincided with Silva M. 2002, ${ }^{61}$ A-alshemkhi $2012^{62}$ and Elnasharty 2013.63 Moreover, SEM examination disclosedthat CVPs were surrounded by a deep moat without an annular pad. The surface had several irregular microridges.These observations were in agreement with Elnasharty 2013, ${ }^{63}$ Kulawik 2013, ${ }^{64}$ Abumandour $2013^{65}$ and $2014 .{ }^{66}$
In goats, there were eight pairs of CVPs and were present on both rims of the torus linguae in the posterior part of the tongueas described in the $\mathrm{ox}^{67}$, camel $^{68}$ and buffalo ${ }^{69}$. Histologically, they were covered with slightly keratinized stratified squamous epithelium and the taste buds were observed only in the medial wall. These were similar to the Iraqi Goat $^{70}$ and Red Sokoto Goats ${ }^{71}$. In SEM, each one was encircled by a prominent gustatory moat and a thick annular pad. These observations were in accordance toKorean native goat, ${ }^{72}$ Jamunapari goats $^{73}$ and Markhoz Iranian goat. ${ }^{74}$

Bargmann $1981^{75}$ explained the presence of ridges, grooves and depressions on CVP surface along with the annular pad as to maintain the saliva thus make certain of more contact with the taste buds. He also suggested that the smooth muscular fibers of the annular pad controlled the access and retention of saliva in the groove. Pastor $2011^{2}$ interpreted the occurrence of these grooves as to increase the gustatory surface of the papilla.

In addition, von Ebner's glands (VEG) areimplicated in washing ofthe furrow surrounding the CVP as well as producing digestiveenzymes, mainly lipases, that are needed mainlyin the neonatal period when the pancreas is still immature. ${ }^{76}$ Kuru et al. $2017^{77}$ suggested that the serous secretions ofVEG preventedapoptosis of taste receptors.

It is noteworthy that the number of CVPs amongst mammals showed a high variability, ranging from none in the cape hyrax ${ }^{78}$. One CVP in rats, ${ }^{45}$ mice,${ }^{31,34}$ and hamsters. ${ }^{35}$ Two CVPs in rabbits, moles, suncuses (insectivora). ${ }^{79,80}$ Three CVPs in koalas ${ }^{81}$ Four CVPs in tiger. ${ }^{82}$ Several CVPs in carnivores like dogs, cats, and raccoon dogs. ${ }^{83} \mathrm{Ten}$ to twenty or more CVPs ingoats and sheep.$^{84,85}$

The variations in food form, feeding habits, food passage and food manipulation along with the methods of food grasping ${ }^{59,65}$ as well as the degree of specialization of the masticatory system ${ }^{86}$ may cause differences in the structure of mammalian tongues. 
In this context, we can speculate that the variances detected in the anatomy of the tongue of these animals may be related to their different feeding habits as omnivore (rat), carnivore (dog).Rabbit and goat are herbivore nevertheless goats belong to the ruminant group of animals. As feeding comprises the taste sense which helpanimals to recognize food that is nutrient-rich and to avoid toxicelements. Also, the smell of food helps the gustatory system in flavor discrimination ${ }^{87}$ and smell disorders as olfactory loss was reported to cause taste loss. ${ }^{88}$

Dogs and rats have a highly advancedability to recognizescents at tiny concentrations. ${ }^{89,90}$ Rabbits also have a well-developed olfactory system with a sharp sense of smell ${ }^{91}$ that help them get their food.On the contrary goats depend on taste in food discrimination of toxic substances. This could explain the presence of several CVPs in goats. Also, it may be emphasized by the supposition of Nonaka et al.2008 22 that thegreater number of CVPin goats was relatedto increased sensitivity in the sense of taste.In addition,Weijnen $2012^{93}$ interpreted the presence of several CVPs in ruminants like goats as they may monitorthe rumination process.

Diet also may control the structure and distribution of papillaeon the tongue surface that characterize each species. Heavy keratinized papillae may be seen in species eating fibrous and solid food. Moreover, species that catches or holds food in their mouths shows characteristic distribution of papillae in groups, so that food may be taken more easily. ${ }^{94}$

Hard-af-Segerstated and Hellekant $1989^{95}$ stated that vallate and foliate papillae contribute in the transduction of sweet taste. Can et al. $2016^{96}$ supposed that the presence of foliate papillae might substitute the presence of few vallate papillae. Foliate papillae do not exist in all animals.In purely meat-eating animals like dogs, and in purely grasseating animals like goats, foliate papillae may have disintegrated through evolutionary processes. ${ }^{92}$
Rats and rabbits have foliate papillae ${ }^{92}$ that may compensate for the single or pair CVP respectively. Moreover, their CVPs have many taste buds distributed on both sides of the circular groove. Dogs lack the foliate papillae $e^{97,92}$ nevertheless have fiveCVPs, each papilla had abundant taste buds in the two sides of the grooves. Goats have no foliate papillae ${ }^{92}$ but have copious CVPson each side, that might elucidate the intensedistribution of taste buds in the medial wall only.

\section{CONCLUSION}

This study pointed outthe morphology and anatomy of CVP in the most commonly used animals in medical research. Also, these noteworthy variations in their microscopic anatomy seamed to represent adaptations to their different feeding behaviours.

\section{REFERENCES}

1. Iwasaki S. Evolution of the structure and function of the vertebrate tongue. J Anat. 2002;201(1):1-13 .

2. Pastor JF, Barbosa M, de Paz FJ, Garcia M, Ferrero E. Functional and comparative study of lingual papillae in four species of bear (Ursidae) by scanning electron microscopy. Microsc Res Tech. 2011;74(10):910-919.

3. Kilinc M, Erdogan S, Ketani S, Ketani MA. Morphological study by scanning electron microscopy of the lingual papillae in the Middle East blind mole rat (Spalax ehrenbergi, Nehring, 1898). Anat Histol Embryol. 2010;39(6):509-515.

4. Mançanares CAF, Santos AC, Piemonte M V, et al. Macroscopic and microscopic analysis of the tongue of the common opossum (Didelphis marsupialis). Microsc Res Tech. 2012;75(10):1329-1333.

5. Heath JW. Oral Tissues. In: Young, B. \& Heath, J.W. (Ed.) Wheater's Functional Histology. 3rd ed. Edinburgh, Churchill Livingstone; 1993.

6. Kobayashi S, Shimamura A. Comparative anatomical observations of the tongue of the Japanese long-fingered bats, Miniopterus schreibersi fuliginosus. Okajimas Folia Anat Jpn. 1982;58(4-6):923-932. 
7. Abumandour MMA, El-Bakary RMA. Morphological and scanning electron microscopic studies of the tongue of the Egyptian fruit bat (Rousettus aegyptiacus) and their lingual adaptation for its feeding habits. Vet Res Commun. 2013;37(3):229-238.

8. Boshell JL, Wilborn WH, Singh BB. Filiform papillae of cat tongue. Acta Anat (Basel). 1982;114(2):97-105.

9. Iwasaki S, Sakata K. Scanning electron microscopy of the lingual dorsal surface of the beagle dog. Okajimas Folia Anat Jpn. 1985;62(1):1-13.

10. Iwasaki S, Miyata K, Kobayashi K. Comparative studies of the dorsal surface of the tongue in three mammalian species by scanning electron microscopy. Acta Anat (Basel). 1987;128(2):140-146.

11. Furubayashi R, Sato E, Ishibashi T. [Histological pattern of the tongue in the Japanese weasels, Mustela itatsi, with special reference to the morphology and distribution of papillae, taste buds and lingual glands]. Kaibogaku Zasshi. 1989;64(3):210-214.

12. Shimoda T, Nakanishi E, Yoshino S, Kobayashi S. Light and scanning electron microscopic study on the lingual papillae in the newborn sea otter Enhydra lutris. Okajimas Folia Anat Jpn. 1996;73(1):65-74.

13. Emura S, Tamada A, Hayakawa D, Chen H, Shoumura S. Morphology of the dorsal lingual papillae in the bush dog (Speothos venaticus). Okajimas Folia Anat Jpn. 2000;77(5):137-141.

14. Emura S, Hayakawa D, Chen H, Shoumura S. Morphology of the dorsal lingual papillae in the newborn panther and Asian black bear. Okajimas Folia Anat Jpn. 2001;78(5):173-177.

15. Jackowiak H, Godynicki S. The scanning electron microscopic study of lingual papillae in the silver fox (Vulpes vulpes fulva, Desmarest, 1820). Ann Anat - Anat Anzeiger. 2004;186(2):179-183.

16. Abayomi TA, Ofusori DA, Ayoka OA, et al. A comparative study of the tongue of rat (Rattus norvegicus), bat (Eidolon helvum) and pangolin (Manis tricuspis). Int J Morphol. 2009;27(4):1111-1119.

17. Kubota K. Guide Book of Anatomy - The Way to Clarification of the Mastication System. Tokyo, Japan: Nihon-Shika-Hyoron; 1988.

18. Iwasaki S, Miyata K, Kobayashi K. Scanning-electronmicroscopic study of the dorsal lingual surface of the squirrel monkey. Cells Tissues Organs, 1988.
19. Iwasaki S, Yoshizawa H, Kawahara I. Study by Scanning Electron Microscopy of the Morphogenesis of Three Types of Lingual Papilla in the Rat. Anat Rec. 1997;247(4):528-541.

20. Qayyum M, Fatani J, Mohajir A. Scanning electron microscopic study of the lingual papillae of the one humped camel, Camelus dromedarius.. J anatomy, 1988.

21. Chamorro C, Fernandez J, Pelaez B. Scanning electron microscopy of the wild boar and pig lingual papillae. Histol and, 1994.

22. Asami Y, Asami T, Kobayashi K. Light microscopic and scanning electron microscopic studies on the lingual papillae and stereo structure of their connective tissue cores in cattle. Shigaku (Odontology), 1995.

23. Kumar P, Kumar S, Singh Y. Tongue Papillae in Goat: a Scanning Electron-Microscopic Study. Anat Histol Embryol J Vet Med Ser C. 1998;27(6):355-357.

24. Emura S, Tamada A, Hayakawa D, Chen H, Shoumura S. Morphology of the dorsal lingual papillae in the barbary sheep, Ammotragus lervia. Okajimas Folia Anat Jpn. 2000;77(2-3):39-45.

25. Suzuki T. Cellular Mechanisms in Taste Buds. Bull Tokyo Dent Coll. 2007;48(4):151-161.

26. Ma H, Yang R, Thomas SM, Kinnamon JC. Qualitative and quantitative differences between taste buds of the rat and mouse. BMC Neurosci. 2007;8:5.

27. Suvarna, Kim S and Layton, Christopher and Bancroft JD. Bancroft's Theory and Practice of Histological Techniques. 8th ed. Elsevier Health Sciences; 2018.

28. Bozzola, John J and Russell LD. Electron Microscopy: Principles and Techniques for Biologists. 2nd ed. Jones \& Bartlett Learning; 1999.

29. Davydova L, Tkach G, Tymoshenko A, et al. Anatomical and morphological aspects of papillae, epithelium, muscles, and glands of rats' tongue: Light, scanning, and transmission electron microscopic study. Interv Med Appl Sci. 2017;9(3):168-177.

30. Scala G, Mirabella N, Pelagalli G V. Morphofunctional study of the lingual papillae in cattle (Bos taurus). Anat Histol Embryol. 1995;24(2):101-105.

31. Petersen CI, Jheon AH, Mostowfi P, et al. FGF Signaling Regulates the Number of Posterior Taste Papillae by Controlling Progenitor Field Size. PLoS Genet. 2011;7(6):e1002098. 
32. Abayomi TA, Ofusori DA, Ayoka OA, et al. A comparative study of the tongue of rat (Rattus norvegicus), bat (Eidolon helvum) and pangolin (Manis tricuspis). Int J Morphol. 2009;27(4):1111-1119.

33. Iwasaki S, Miyata K, Kobayashi K. Scanning-electronmicroscopic study of the dorsal lingual surface of the squirrel monkey. Acta Anat (Basel). 1988;132(3):225-229.

34. Kobayashi K, Miyata K, Takahashi K, Iwasaki S. [Threedimensional architecture of the connective tissue papillae of the mouse tongue as viewed by scanning electron microscopy]. Kaibogaku Zasshi. 1989;64(6):523-538.

35. Kitajima K, Kobayashi K. Light and electron microscopic studies on the lingual papillae and their connective tissue cores in hamster. Japanese J Oral Biol. 1992.

36. Jackowiak H, Godynicki S. The distribution and structure of the lingual papillae on the tongue of the bank vole Clethrinomys glareolus. Folia Morphol (Warsz). 2005;64(4):326-333.

37. Kilinc M, Erdogan S, Ketani S, Ketani MA. Morphological study by scanning electron microscopy of the lingual papillae in the Middle East blind mole rat (Spalax ehrenbergi, Nehring, 1898). Anat Histol Embryol. 2010;39(6):509-515.

38. Kobayashi K. Three-dimensional architecture of the connective tissue core of the lingual papillae in the guinea pig. Anat Embryol (Berl). 1990;182(3):205-213.

39. Emura S, Tamada A, Hayakawa D, et al. SEM study on the dorsal lingual surface of the flying squirrel, Petaurista leucogenys. Ann Anat. 1999;181(5):495-498.

40. Chunhabundit P, Thongpila S, Somana R. SEM study on the dorsal lingual surface of the common tree shrew, Tupaia glis. Acta Anat (Basel). 1992;143(3):253-257.

41. Shindo J, Yoshimura K, Kobayashi K. Comparative morphological study on the stereo-structure of the lingual papillae and their connective tissue cores of the American beaver (Castor canadensis). Okajimas Folia Anat Jpn. 2006;82(4):127-137.

42. Al-Refai AS, Omar OA KA. Effect of chamomile extract on the tongue of chemotherapy treated albino rats (histopathological and immunohistochemical study). J Clin Cell Immunol. 2014;05(04):1-8.

43. Goździewska-Harłajczuk K, Klećkowska-Nawrot $\mathrm{J}$, Barszcz K, et al. Biological aspects of the tongue morphology of wild-captive WWCPS rats: a histological, histochemical and ultrastructural study. Anat Sci Int. 2018;93(0123456789):514-532.

44. Costa ACBP, Pereira CA, Junqueira JC, Jorge AOC. Recent mouse and rat methods for the study of experimental oral candidiasis. Virulence. 2013;4(5):391-399.

45. Reginato G de S, Bolina C de S, Watanabe I, Ciena AP. ThreeDimensional Aspects of the Lingual Papillae and Their Connective Tissue Cores in the Tongue of Rats: A Scanning Electron Microscope Study. Sci World J. 2014:1-6.

46. Verli FD, Marinho SA, Rossi-Schneider TR, Yurgel LS, de Souza MAL. Angioarchitecture of the ventral surface of the tongue from Wistar rats. Scanning. 2008;30(5):414418.

47. Hosley MA, Oakley B. Postnatal development of the vallate papilla and taste buds in rats. Anat Rec. 1987;218(2):216222.

48. Wakisaka S, Daikoku H, Miyawaki Y, Youn SH, Kurisu K, Maeda T. Immunohistochemical observation of growth-associated protein 43 (GAP-43) in the developing circumvallate papilla of the rat. Cell Tissue Res. 1998;293(3):499-507.

49. Triantafyllou A, Fletcher D, Scott J. Lipolytic and esterolytic activities in posterior lingual glands of rat: a histochemical study. Histochem J. 2002;34(11-12):529533.

50. Picoli LC, Lopes RA, Semprini M, Sala MA, Ogawa K, Watanabe IS. Transmission electron microscopy study of the neonatal rat tongue mucosa treated with special attention to the bacteriae on the epithelial cell membrane. Int J Morphol. 2006;24(2):159-163.

51. El Sharaby AA, El-Gendy SA, Alsafy MA, Nomir AG, Wakisaka S. Morphological variations of the vallate papillae in some mammalian species. Anat Sci Int. 2014;89(3):161-170.

52. Yucel F, Akdoğan I, Güven G, Ortuğ G. SEM examination of the dorsal lingual papillae of pregnant rats. Ann Anat. 2002;184(3):251-255.

53. Ghazale and Frangis. Macroscopic and Microscopic Study of Tongue. Indian J Fundam Appl Life Sci. 2013;3(4): $39-44$.

54. El Sharaby AA, El-Gendy SA, Alsafy MA, Nomir AG, Wakisaka S. Morphological variations of the vallate papillae in some mammalian species. Anat Sci Int. 2014;89(3):161-170. 
55. Goździewska- Harłajczuk K, Klećkowska-Nawrot $\mathrm{J}$, Barszcz K, et al. Biological aspects of the tongue morphology of wild-captive WWCPS rats: a histological, histochemical and ultrastructural study. Anat Sci Int. 2018;93(0123456789):514-532 .

56. Kobayashi K. Developmental and Morphological Changes in Dog Lingual Papillae and Their Connective Tissue Papillae. In Proc. 6th International M. Singer Symp; 1988.

57. Kobayashi K. Three-dimensional architecture of the connective tissue core of the lingual papillae in the guinea pig. Anat Embryol (Berl). 1990;182(3):205-213.

58. Emura S, Okumura T, Chen H, Shoumura S. Morphology of the lingual papillae in the raccoon dog and fox. Okajimas Folia Anat Jpn. 2006;83(3):73-76

59. Chamorro CA, de Paz P, Sandoval J, Fernandez JG. Comparative scanning electron-microscopic study of the lingual papillae in two species of domestic mammals (Equus caballus and Bos taurus). 1. Gustatory Papillae. Acta Anat (Basel). 1986;125(2):83-87.

60. Kobayashi K, Jackowiak H, Frackowiak H, Yoshimura K, Kumakura M, Kobayashi K. Comparative morphological study on the tongue and lingual papillae of horses (Perissodactyla) and selected ruminantia (Artiodactyla). Ital J Anat Embryol. 2005;110(2 Suppl 1):55-63.

61. M.Silva IW and MCK. Three-dimensional architecture of the connective tissue core the rabbit. Anat Embryol (Berl). 2002;182(3):455-461.

62. A-alshemkhi MAR. Light microscopy study of lingual papillae in rabbits ( oryctolagus cuniculus ). 2012;4(2).

63. Elnasharty M, El Sharaby A, Nor El-din A. Histogenesis of Rabbit Vallate Papillae. Int J Biol Biomol Agric Food Biotechnol Eng. 2013;7(4):261-268.

64. Kulawik M, Godynicki S, Frackowiak H. Light microscopic observations of vallate papillae in prenatal and postnatal periods of rabbit (Oryctolagus cuniculus $\mathrm{f}$. domestica). Electron J Polish Agric Univ Ser Anim Husb. 2013;16(3).

65. Abumandour MMA, El-Bakary RMA. Anatomic reference for morphological and scanning electron microscopic studies of the New Zealand white rabbits tongue (Orycotolagus cuniculus) and their lingual adaptation for feeding habits. J Morphol Sci. 2013;30(4):254-265.

66. Abumandour MMA. Morphological comparison of the filiform papillae of New Zealand white rabbits (Oryctolagus
Cuniculus) as domestic mammals and Egyptian fruit bat (Rousettus Aegyptiacus) as wild mammals using scanning electron microscopic specimens. Int J Morphol. 2014;32(4):1407-1417.

67. de Paz Cabello P, Chamorro CA, Sandoval J, Fernandez M. Comparative scanning electron-microscopic study of the lingual papillae in two species of domestic mammals (Equus caballus and Bos taurus). II. Mechanical papillae. Acta Anat (Basel). 1988;132(2):120-123.

68. Qayyum MA, Fatani JA, Mohajir AM. Scanning electron microscopic study of the lingual papillae of the one humped camel, Camelus dromedarius. J Anat. 1988;160:21-26.

69. Scala G, Pelagalli G V., Vittoria A, Girolamo P DE. Etude Morpho-Structurale des Papilles Linguales chez le Buffle (Bubalus bubalis). Anat Histol Embryol J Vet Med Ser C. 1993;22(3):264-272.

70. Jabbar AI. Macroscopical and Microscopical Observations of the Tongue in the Iraqi Goat (Capra hircus). Int J Adv Res. 2014;2(6):642-648.

71. Igbokwe CO, Okolie C. The Morphological Observations of Some Lingual Papillae in the Prenatal and Prepuberal Stages of Red Sokoto Goats (Capra hircus). Int J Morphol. 2009;27(1):145-150.

72. Cho G, Kim M, Lee S, Kim C, Won C. Scanning Electron Microscopic Study of the Developing Vallate Papillae in the Korean Native Goat ( Capra hircus ). Dev Reprod. 2016;20(4):283-288.

73. Kumar P, Kumar S, Singh Y. Tongue papillae in goat: a scanning electron-microscopic study. Anat Histol Embryol. 1998;27(6):355-357.

74. Goodarzi N, Hoseini TS. Fine Structure of Lingual Papillae in the Markhoz Goat (Iranian Angora): A Scanning Electron Microscopic Study. Int J Zool Res. 2015;11(4):160-168.

75. Wolfgang Bargmann. Histología y Anatomía Microscópica Humanas. 4a ed. Barcelona : Espaxs; 1981.

76. Sbarbati A, Crescimanno C, Osculati F. The anatomy and functional role of the circumvallate papilla/von Ebner gland complex. Med Hypotheses. 1999;53(1):40-44.

77. Kuru N, Çinar K, Demirbag E, Ilgün R. Histological and histochemical structure of lingual salivaryglands in mole rat (Spalax leucodon). Indian J Anim Res. 2016;(OF).

78. Yoshimura K, Hama N, Shindo J, Kobayashi K, Kageyama I. Light and scanning electron microscopic study on the 
lingual papillae and their connective tissue cores of the Cape hyrax Procavia capensis. J Anat. 2008; 213(5): 573-582.

79. Kobayashi S, Arai S, Tomo S, Shimoda T, Shimamura A, Yamada H. Scanning electron microscopic study on the lingual papillae of the Japanese insectivora. Okajimas Folia Anat Jpn. 1989;65(6):413-427.

80. Miyata K, Iwasaki S, Kobayashi K. Fine morphological studies on the connective tissue core and the epithelial cells of the lingual papillae in Mogella wogura wogura. Shigaku. 1990;78(3):553-574.

81. Kobayashi K, Kumakura M, Yoshimura K, Nonaka K, Murayama T, Henneberg M. Comparative morphological study of the lingual papillae and their connective tissue cores of the koala. Anat Embryol (Berl). 2003;206(4):247254.

82. Emura S, Hayakawa D, Chen H, Shoumura S. Morphology of the lingual papillae in the tiger. Okajimas Folia Anat Jpn. 2004;81(2-3):39-43.

83. Kobayashi K, Miyata K, Iwasaki S, Takahashi K. Three dimensional structure of the connective tissue papillae of cat lingual papillae. Japanese J Oral Biol. 1988;30(6):719731 .

84. Inatomi M, Kobayashi K. Comparative morphological studies on the tongue and lingual papillae of the Japanese black bear (Carnivora) and the mountain goat (Artiodactyla). ODONTOLOGY-TOKYO. 1999;87(3):313-328.

85. Yamaguchi T, Asami T, Kobayashi K. Comparative Anatomical Studies on the Stereo Structure of the Lingual Papillae and Their Connective Tissue Cores in the Japanese Serow and Bighorn Sheep. Japanese J Oral Biol. 2002;44(2):127-141.

86. Sako N, Shimura T, Komure M, Mochizuki R, Matsuo R, Yamamoto T. Differences in taste responses to Polycose and common sugars in the rat as revealed by behavioral and electrophysiological studies. Physiol Behav. 1994; 56(4):741-745.

87. Larry Squire, Darwin Berg FE, Squire LR. Fundamental Neuroscience. Elsevier/Academic Press; 2013.

88. Deems DA, Doty RL, Settle RG, et al. Smell and Taste Disorders, A Study of 750 Patients From the University of Pennsylvania Smell and Taste Center. Arch Otolaryngol Head Neck Surg. 1991;117(5):519-528.

89. Quignon P, Giraud M, Rimbault M, et al. The dog and rat olfactory receptor repertoires. Genome Biol. 2005;6(10):R83.

90. Padodara RJ and NJ. Olfactory Sense in Different Animals. Indian J Vet Sci. 2014;2(1):1-14.

91. Smith MH, Meehan CL, Ma JM, et al. Rabbits: From the Animal's Point of View, 3: Rabbit Nutrition: Whay You Need to Know.; 2009.

92. Nonaka K, Zheng JH, Kobayashi K. Comparative morphological study on the lingual papillae and their connective tissue cores in rabbits. Okajimas Folia Anat Jpn. 2008;85(2):57-66.

93. Weijnen J.A. W. M. Drinking Behavior: Oral Stimulation, Reinforcement, and Preference. Springer Science \& Business Media; 2012.

94. Iwasaki SI. Evolution of the structure and function of the vertebrate tongue. J Anat. 2002;201(1):1-13.

95. Hard af Segerstad CH, Hellekant G. The sweet taste in the calf. II. Glossopharyngeal nerve responses to taste stimulation of the tongue. Physiol Behav. 1989;45(5):10431047.

96. Can M, Atalgin ŞH, Aydin MF. Scanning Electron Microscopic Studies of the Lingual Papillae in the English Horse. Acta Vet Brno. 2016;66(2):257-264.

97. Boshel J, Wilborn WH, Singh BB. Filiform Papillae of Cat Tongue. Cells Tissues Organs. 1982;114(2):97-105. 